\title{
Notas sobre a participação não-eleitoral no Nordeste
}

\section{Evelina Antunes F. de Oliveira}

Universidade Federal de Alagoas

\section{Resumo}

A autora enfoca o apoio ao sistema democrático através do grau de participação política não-eleitoral. Especificamente estuda as características da participação na região Nordeste do Brasil. O artigo utiliza os dados do ESEB 2002.

Palavras-chave: Estudo Eleitoral Brasileiro; participação; comportamento associativo; Nordeste

\section{Abstract}

The author focus on the support to democratic system by analysing the level of non-electoral political participation. Specifically she studies the characteristics of participation in the Brazilian Northeast Region. The data come from the 2002 Brazilian Electoral Study.

Keywords: Brazilian Electoral Study; participation; associative behavior; Northeast 


\section{Introdução ${ }^{1}$}

Estudos pré e pós-eleitorais, como as pesquisas de opinião, têm objetivos de curto e médio prazos, servindo para abordar questões relativas tanto a conjunturas quanto a estruturas políticas. Enquanto os primeiros orientam candidaturas e, em menor escala, as opções dos eleitores, trabalhando elementos do imaginário e expressando práticas sociais efetivas, os segundos, além de poderem municiar eleições e eleitores, sustentam pesquisas sobre o comportamento político. É o caso do Estudo Eleitoral Brasileiro (ESEB) 2002.

Neste artigo, serão analisados indicadores de uma de suas variáveis mais relevantes - o apoio ao sistema político democrático - a partir da abordagem qualitativa de algumas perguntas sobre a participação não-eleitoral. O pressuposto é que práticas sociais institucionalizadas e de natureza associativa interferem nas opções dos eleitores e concorrem para a construção de visões mais amplas de política e de sociedade.

O debate sobre o papel destas práticas e do comportamento político para a consolidação da democracia avançou nos últimos dois séculos ao menos a partir de duas vertentes, uma que aborda a democracia do ponto de vista institucional (MILL, 1981) e outra que a aborda na perspectiva da cultura política (TOCQUEVILLE, 1964).

Os dois enfoques concordam, não obstante, que os cidadãos são ativos e capazes de agir com liberdade para realizar seus interesses. Para Mill, a perspectiva da participação popular nas decisões públicas está orientada para atuar institucionalmente e, neste sentido, cada vez mais setores da sociedade são incorporados. Já Tocqueville considera que a democracia é assegurada principalmente através da ação política propiciada pelas instituições associativas da vida civil próprias de cada sociedade e as mais capacitadas para defender a cidadania.

O comportamento político constrói-se tanto a partir dos meios de atuação direta como pelas vias da representação - eleições, partidos e parlamento - e não apenas a partir da democracia semidireta, como foi cuidadosamente explicado por Benevides (1996), para a constituição do poder legislativo no Brasil, mas também no que diz respeito às representações de interesses que não almejam unicamente o acesso ao poder.

\footnotetext{
${ }^{1}$ Agradeço a colaboração na seleção dos dados a Ana Glória Ferreira, Nicolas Tavares Cruz, Ranulfo Paranhos Filho e Tércio Bezerra Terencio.
} 
Sobre o poder legislativo como depositário do ideal clássico dos limites à participação popular, Lima Júnior (1997) identifica certos constrangimentos nas democracias contemporâneas: uma crise generalizada no sistema de representação além do crescimento de outras formas de atuação no sistema político.

Avritzer, a propósito da teoria habermasiana, vincula a efetividade democrática aos processos normativos do mundo da vida, resultantes dos meios da democracia formal e da cultura democrática. "Tais processos estão ligados à formação de associações e à reprodução da solidariedade social (AVRITZER, 1996, p. 20).

As diferentes maneiras de participar convergem para a valorização do espaço público como locus privilegiado da participação. Para este convergem as vias institucionais e/ou culturais, é onde a democracia se realiza com mais intensidade e é, portanto, de onde poderá sair sua renovação.

Esse potencial inovador mostra-se cada vez mais complexo, e seu estudo aponta os dilemas de funcionamento e organização. Existem imperativos burocráticos? Estariam mesmo sendo processados valores diferentes daqueles produzidos pelos padrões oligárquicos e personalistas com os quais estamos acostumados?

A definição de participação política a partir da condição de pertencimento a uma pólis não permite explicar a pluralidade e a diversidade das atuais formas de participação não-eleitoral. 0 problema mais complicado parece estar na forma de contrato que se estabelece entre essas ações de grupos e o próprio espaço público. Qual autoridade seria capaz de gerenciar tudo isso?

Doimo (1997) enfoca a discussão da ação direta dos movimentos sociais. Em um movimento contrário ao que vem ocorrendo na Europa nos últimos trinta anos, os brasileiros organizados são em sua maioria pobres, não têm definição ideológica e querem solução para problemas urgentes de sobrevivência. 0 impasse em relação ao Estado emerge quando o sentido de suas ações oscila entre a contestação e a legitimidade, posto que a resposta positiva às suas reivindicações depende do grau em que se tornam corporativos e burocráticos e de quando seus ganhos podem ser usufruídos pela comunidade, sem necessariamente gerar sociabilidade coletiva.

Para Sandoval (1997), o problema reside no momento e nas condições da passagem do ator social para o ator coletivo. Segundo o autor, os esforços de pesquisa têm procurado demonstrar que os indivíduos não realizam seus interesses em espaços coletivos de modo passivo, como era anteriormente explicado.

Esse suposto de racionalidade é abordado por Reis e Machado como decorrência do viés ideológico presente nos estudos eleitorais. Advertem: aquilo que a ação política desencadeada nos movimentos [...] procura fazer [...] (é) transformar o fundamento da identidade coletiva numa questão de opção voluntária (REIS e MACHADO, 1992, p. 84). E lembram que escolhas se fazem a partir do conhecimento sobre as opções possíveis. 
As democracias consolidadas têm resultados a compreender, avaliar e comparar. Para o caso brasileiro, Lima e Cheibub, analisando os dados de um survey sobre cultura política de quatro setores da elite, entre 1993 e 1994, concluem que ocorre uma valorização da política institucional "não se estendendo às relações sociais, em especial na dimensão da igualdade" (LIMA \& CHEIBUB, 1996, p. 98) e que mudanças nas instituições políticas conjugam valores não-democráticos de cultura política (idem, p. 101).

Santos (2003) enfatiza a expansão, nos últimos cinqüenta anos, da mobilização eleitoral e da vida associativa em cada uma das regiões do país. Também Meneguello, analisando dados recentes de pesquisa sobre partidos políticos no Brasil, confirma uma tendência mundial à adesão aos valores democráticos, mas acompanhada de forte queda na confiança em instituições (MENEGUELLO, 2003, p. 347). Ao confirmar para a democracia brasileira uma ampla base de massa, que favorece mais uma vez apelos populistas e personalistas que poderiam fragilizar o sistema partidário, mostra, no entanto, que se consolidam preferências entre os eleitores com referência aos partidos como orientação de escolhas (idem, p. 349).

Se há otimismo em relação às chances de atuação na cena pública, os debates teóricos sugerem atenção aos sentidos e aos valores que impulsionam essas variadas formas de participação.

Para o que se coloca nos limites deste trabalho, complexidade, diversidade e múltiplas direções constituem os traços marcantes das possibilidades de participação não-eleitoral. O ESEB possibilita cruzamentos quanto a opiniões, atitudes, valores e ação institucional, mas o propósito deste artigo é apenas caracterizar as instituições associativas através da análise das respostas a perguntas simples e diretas e sua relação com a população nordestina.

A seleção destas perguntas levou em conta o fato de que em Alagoas, Pernambuco e Sergipe elas não apresentaram "ruídos de comunicação" entre entrevistadores e entrevistados. O recorte regional baseia-se numa dimensão importante das pesquisas sociais, que é a contextualização do tema e do modo de realização da investigação. Assim, a regionalidade emerge como fator diferencial na reflexão sobre questões de sociabilidade e seu potencial de ação política, podendo gerar comparações entre especificidades, não apenas territoriais mas também de comportamento.

Um outro ponto importante do aspecto regional aponta para a descentralização política e administrativa em curso no Brasil, através da qual o poder central vem gradativamente perdendo sua primazia sobre os arranjos políticos locais, que reemergem e dão maior visibilidade às particularidades regionais (CASTRO \& CARVALHO, 2002). 


\section{Aspectos da participação não-eleitoral}

Acompanhando os dados para o total de entrevistas do ESEB no país, são expressivos os números de entrevistados que, no Nordeste, não estão filiados a associações profissionais (88\%), sindicatos $(79,4 \%)$ e partidos políticos $(94 \%)$ e nem participam de greves $(66 \%)$ ou manifestações e protestos $(63 \%)$.

Mas do total de entrevistados nordestinos com algum pertencimento institucional, o perfil é o que segue. A maioria dos nordestinos filiados a sindicatos (77,3\%) e partidos políticos $(56,8 \%)$ têm mais de 35 anos, mas menos da metade dos entrevistados desta faixa etária pertence a uma associação profissional. (Tabela 1)

Tabela 1

Filiação e Faixa Etária no Nordeste

\begin{tabular}{l|l|r|r|r}
\hline & Faixa Etária & Não-filiado & Filiado & Total \\
\hline \multirow{4}{*}{ Associação profissional } & 16 a 24 anos & 101 & 18 & 119 \\
\cline { 2 - 5 } & 25 a 34 anos & 119 & 24 & 143 \\
\cline { 2 - 5 } & 35 anos ou mais & 321 & 32 & 353 \\
\cline { 2 - 5 } & Total & $\mathbf{5 4 1}$ & $\mathbf{7 4}$ & $\mathbf{6 1 5}$ \\
\hline \multirow{5}{*}{ Sindicato } & 16 a 24 anos & 117 & 5 & 122 \\
\cline { 2 - 5 } & 25 a 34 anos & 119 & 24 & 143 \\
\cline { 2 - 5 } & 35 anos ou mais & 257 & 99 & 356 \\
\cline { 2 - 5 } & Total & $\mathbf{4 9 3}$ & $\mathbf{1 2 8}$ & $\mathbf{6 2 1}$ \\
\hline Partido & 16 a 24 anos & 115 & 7 & 122 \\
\cline { 2 - 5 } & 25 a 34 anos & 133 & 9 & 142 \\
\cline { 2 - 5 } & 35 anos ou mais & 333 & 21 & 354 \\
\cline { 2 - 5 } & Total & $\mathbf{5 8 1}$ & $\mathbf{3 7}$ & $\mathbf{6 1 8}$ \\
\hline
\end{tabular}

Fonte: ESEB 2002.

Quanto à escolaridade, mais de $80 \%$ de todos os filiados tiveram acesso à escola e, majoritariamente, escola pública. Entretanto, levando em conta suas idades, assim como o fato de que algumas melhorias no sistema de ensino em todo o Brasil ocorreram a partir dos últimos dez anos, é possível questionar a qualidade da formação escolar que caracteriza boa parte desses eleitores. Por outro lado, é também significativo que $17 \%$ dos sindicalizados nunca tenham freqüentado escola ${ }^{2}$. (Tabela 2)

\footnotetext{
2 Vale observar que, segundo o CENSO 2000 para os estados do Nordeste, há, em média, 32\% de pessoas sem instrução e com menos de 1 ano de estudo e 35\% de pessoas que têm entre 1 e 4 anos de estudo.
} 
OPINIÃO PÚBLICA, Campinas, Vol. X, no 2, Outubro, 2004, p. 377-388

Tabela 2

Acesso à escola e filiação no Nordeste

\begin{tabular}{l|r|r|r|r|r|r|r|r|r}
\hline Acesso à escola & \multicolumn{4}{|c|}{ Associação Profissional } & \multicolumn{3}{c|}{ Partido } & \multicolumn{3}{c}{ Sindicato } \\
\hline & Não & Sim & Total & Não & Sim & Total & Não & Sim & Total \\
\hline Pública & 393 & 42 & 435 & 412 & 25 & 437 & 361 & 77 & 438 \\
\hline Particular & 49 & 13 & 62 & 57 & 5 & 62 & 45 & 17 & 62 \\
\hline Pública e particular & 38 & 9 & 47 & 45 & 5 & 50 & 40 & 10 & 50 \\
\hline Nunca freqüentou & 58 & 8 & 66 & 65 & 2 & 67 & 45 & 22 & 67 \\
\hline Total & $\mathbf{5 3 8}$ & $\mathbf{7 2}$ & $\mathbf{6 1 0}$ & $\mathbf{5 7 9}$ & $\mathbf{3 7}$ & $\mathbf{6 1 6}$ & $\mathbf{4 9 1}$ & $\mathbf{1 2 6}$ & $\mathbf{6 1 7}$ \\
\hline
\end{tabular}

Fonte: ESEB 2002.

Segundo o Censo Demográfico de 2000, 27\% dos nordestinos com mais de 10 anos de idade têm até um salário mínimo como renda nominal mensal e 49\% se declaram sem rendimentos. Este quadro se repete entre os que pertencem a entidades representativas: $27,5 \%$ dos pertencentes a associações profissionais, $32,7 \%$ dos sindicalizados e $30 \%$ dos filiados a partidos têm renda familiar mensal de até um salário mínimo.(Tabela 3)

Tabela 3

Renda mensal familiar (R\$) e filiação no Nordeste

\begin{tabular}{l|r|r|r|r|r|r|r|r|r}
\hline \multicolumn{1}{c|}{ Renda } & \multicolumn{3}{|c|}{ Associação Profissional } & \multicolumn{3}{c|}{ Sindicato } & \multicolumn{3}{c}{ Partido político } \\
\hline & Não & \multicolumn{1}{|c|}{ Sim } & \multicolumn{1}{c|}{ Total } & \multicolumn{1}{c|}{ Não } & \multicolumn{1}{c|}{ Sim } & \multicolumn{1}{c|}{ Total } & \multicolumn{1}{c}{ Não } & \multicolumn{1}{c}{ Sim } & \multicolumn{1}{c}{ Total } \\
\hline Sem renda & 10 & 1 & 11 & 9 & 1 & 10 & 10 & - & 10 \\
\hline Até 240,00 & 151 & 19 & 170 & 138 & 35 & 173 & 161 & 10 & 171 \\
\hline $250,00-750,00$ & 211 & 31 & 242 & 190 & 50 & 240 & 225 & 17 & 242 \\
\hline $800,00-1.300,00$ & 46 & 5 & 51 & 44 & 7 & 51 & 49 & 2 & 51 \\
\hline $1.400,00-2.000,00$ & 21 & 6 & 27 & 17 & 9 & 26 & 22 & 3 & 25 \\
\hline $2.500,00-3.500,00$ & 7 & 0 & 7 & 6 & 1 & 7 & 6 & 1 & 7 \\
\hline $4.000,00$ acima & 10 & 7 & 17 & 13 & 4 & 17 & 17 & 0 & 17 \\
\hline Total & $\mathbf{4 5 6}$ & $\mathbf{6 9}$ & $\mathbf{5 2 5}$ & $\mathbf{4 1 7}$ & $\mathbf{1 0 7}$ & $\mathbf{5 2 4}$ & $\mathbf{4 9 0}$ & $\mathbf{3 3}$ & $\mathbf{5 2 3}$ \\
\hline
\end{tabular}

Fonte: ESEB 2002.

Este é o mesmo perfil que caracteriza os quase $23 \%(22,8 \%)$ de entrevistados que declararam participar ou já ter participado de associações de moradores. Assim, entre os que declararam participar, 85,6\% têm renda mensal familiar de até $R \$ 750,00$ (Tabela 4). Para este conjunto de entrevistados também se repetem as características de acesso à escola e faixa etária, com a predominância de indivíduos com acesso à escola pública e com 35 anos ou mais de idade. (Tabelas 4 e 5) 
Tabela 4

Renda mensal familiar (R\$) e participação em associação de moradores no Nordeste

\begin{tabular}{l|c|c|c|c}
\hline & $\begin{array}{c}\text { Não } \\
\text { participa }\end{array}$ & $\begin{array}{c}\text { Participou, } \\
\text { mas não participa } \\
\text { mais }\end{array}$ & Participa & Total \\
\hline Sem renda & 9 & 1 & 18 & 160 \\
\hline Até 240,00 & 117 & 25 & 21 & 234 \\
\hline $250,00-750,00$ & 179 & 34 & 5 & 51 \\
\hline $800,00-1.300,00$ & 40 & 6 & 2 & 26 \\
\hline $1.400,00-2.000,00$ & 24 & 0 & 0 & 7 \\
\hline $2.500,00-3.500,00$ & 6 & 1 & 0 & 17 \\
\hline $4.000,00$ acima & 16 & 1 & $\mathbf{4 6}$ & $\mathbf{5 0 5}$ \\
\hline Total & $\mathbf{3 9 1}$ & $\mathbf{6 8}$ & & 10 \\
\hline
\end{tabular}

Fonte: ESEB 2002.

Tabela 5

Participação em associação de moradores, acesso à escola e faixa etária no Nordeste

\begin{tabular}{|c|c|c|c|c|c|}
\hline \multirow{6}{*}{$\begin{array}{l}\text { Acesso } \\
\text { à escola }\end{array}$} & & $\begin{array}{c}\text { Não } \\
\text { participa }\end{array}$ & $\begin{array}{c}\text { Participou, } \\
\text { mas não participa mais }\end{array}$ & Participa & Total \\
\hline & Pública & 323 & 55 & 40 & 418 \\
\hline & Particular & 47 & 10 & 4 & 61 \\
\hline & Pública e particular & 41 & 5 & 2 & 48 \\
\hline & Nunca freqüentou & 47 & 5 & 7 & 59 \\
\hline & Total & 458 & 75 & 53 & 586 \\
\hline \multirow{4}{*}{$\begin{array}{l}\text { Faixa } \\
\text { Etária }\end{array}$} & 16 a 24 anos & 101 & 8 & 7 & 116 \\
\hline & 25 a 34 anos & 112 & 14 & 13 & 139 \\
\hline & 35 anos ou mais & 247 & 54 & 34 & 335 \\
\hline & Total & 460 & 76 & 54 & 590 \\
\hline
\end{tabular}

Fonte: ESEB 2002. 
Este perfil altera-se um pouco quando analisamos os dados sobre a expectativa de participação em greves e manifestações e protestos. Entre todos os entrevistados do Nordeste, 32\% participariam de greves. Destes, $75 \%$ têm renda mensal familiar de até $\mathrm{R} \$ 750,00$. (Tabela 6)

Tabela 6

Renda mensal familiar, acesso à escola e expectativa de participação em greves no Nordeste

\begin{tabular}{l|c|c|c}
\hline Renda mensal familiar & Não participaria & Participaria & Total \\
\hline Sem renda & 6 & 4 & 10 \\
\hline Até 240,00 & 116 & 55 & 171 \\
\hline $250,00-750,00$ & 161 & 75 & 236 \\
\hline $800,00-1.300,00$ & 34 & 18 & 52 \\
\hline $1.400,00-2.000,00$ & 11 & 14 & 25 \\
\hline $2.500,00-3.500,00$ & 6 & 2 & 8 \\
\hline $4.000,00$ acima & 8 & 7 & 15 \\
\hline Total & $\mathbf{3 4 2}$ & $\mathbf{1 7 5}$ & $\mathbf{5 1 7}$ \\
\hline Acesso à escola & & & \\
\hline Pública & 287 & 146 & 433 \\
\hline Particular & 41 & 18 & 59 \\
\hline Pública e particular & 30 & 17 & 47 \\
\hline Nunca freqüentou & 53 & 12 & 65 \\
\hline Total & $\mathbf{4 1 1}$ & $\mathbf{1 9 3}$ & $\mathbf{6 0 4}$ \\
\hline
\end{tabular}

Fonte: ESEB 2002. 
Entre os que participariam de manifestações ou protestos, 46\% têm até 34 anos. Para os que declaram que participariam de manifestações e protestos, apenas destacamos sua faixa etária: $46 \%$ dos entrevistados estão nas duas faixas mais jovens, com até 34 anos. (Tabela 7)

\section{Tabela 7}

Faixas de idade e expectativa de participação em manifestações ou protestos no Nordeste

\begin{tabular}{l|c|c|c}
\hline & \multicolumn{2}{|c|}{ Participaria de manifestações ou protestos } & \\
\hline Idade & Não & Sim & Total \\
\hline 16 a 24 anos & 73 & 45 & 118 \\
\hline 25 a 34 anos & 85 & 56 & 141 \\
\hline 35 anos ou mais & 220 & 121 & 341 \\
\hline Total & 378 & 222 & 600 \\
\hline
\end{tabular}

Fonte: ESEB 2002.

\section{Conclusões Preliminares}

Ainda que as comparações aqui feitas sejam tímidas para sustentar generalizações, sugerem dimensões importantes para pensar as condições de participação não-eleitoral no Nordeste. Talvez, a indicação mais importante seja um certo alheamento quanto às questões públicas. Uma tendência que se apresenta é o crescimento do interesse, entre os mais jovens, na participação em manifestações mais pontuais, como greves ou protestos. O caráter festivo que manifestações desse tipo assumem na região, por exemplo, é um fator ainda a ser estudado ${ }^{3}$. Podemos sugerir que, se a atuação associativa altera a visão de mundo e o comportamento, o tradicionalismo nordestino precisa entrar na pauta de discussão.

Essas aproximações devem ser confrontadas com as tendências mais marcantes apontadas pelo ESEB sobre o próprio comportamento eleitoral, seja na ótica dos valores e atitudes, seja na ótica de suas relações institucionais.

\footnotetext{
3 Em Maceió, por exemplo, é comum carros de som acompanharem manifestações, e o forró ou o pagode tornarem-se um atrativo maior que o discurso político .
} 


\section{Bibliografia}

ATLAS das eleições presidenciais e municipais no Brasil. In: Alceu Revista de Comunicação e Cultura. Rio de Janeiro: PUCRJ, 2002. 1 CD-ROM

AVRITZER, Leonardo. A moralidade da democracia; ensaios em teoria habermasiana e teoria democrática. São Paulo: Perspectiva; Belo Horizonte: Editora da UFMG, 1996.

BALBACHEVSKY, Elizabeth. Liberdade e representação. In: STUART MILL. Os clássicos da política. Cap. 6, p. 189-223, 1989.

BAQUERO, Marcello. Opinião pública e pesquisas eleitorais. In: LHULLIER, Louise et al (Org.). Estudos sobre comportamento político: teoria e pesquisa. Florianópolis: Letras Contemporâneas, p. 57-68, 1997.

BENEVIDES, Maria Victória de Mesquita. Nós, o povo: reformas políticas para radicalizar a democracia. In: BENEVIDES, M.V; KERCHE, F.; VANNUCHI (Orgs.). Reforma política e cidadania. São Paulo: Editora Fundação Perseu Abramo, p. 83-119, 2003.

. A cidadania ativa: referendo, plebiscito e iniciativa popular. São Paulo: Ática, 1996.

BOBBIO, Norberto. Liberalismo e democracia. São Paulo: Brasiliense, 1988. $\overline{\text { Terra, } 1987 .}$

Estado, governo e sociedade: Para uma teoria geral da política. Rio de Janeiro: Paz e

CARDOSO, Ruth C. L. Participação política e democracia. Novos estudos CEBRAP, n. 26, p.15-24, 1990.

CASTRO, Marcos Faro de; CARVALHO, Maria Izabel Valladão. Globalização e transformações políticas recentes no Brasil: os anos 90. Revista de Sociologia e Política, n. 18, p. 109-129, 2002.

DOIMO, Ana Maria. Movimentos sociais e participação política: a problemática contemporânea da ação direta. In: LHULLIER, Louise et al (Org.). Estudos sobre comportamento político: teoria e pesquisa. Florianópolis: Letras Contemporâneas, p. 129-147, 1997.

ESEB. Estudo Eleitoral Brasileiro. Banco de Dados. FGV Opinião, Rio de Janeiro, 2002.

ESEB. Estudo Eleitoral Brasileiro. Relatório dos entrevistadores. Alagoas, Pernambuco e Sergipe. Maceió, 2003. 
IBGE. Censo 2000.

LEFORT, Claude. A invenção democrática: os limites da dominação totalitária. São Paulo: Brasiliense, 1997.

LIMA, Maria Regina Soares; CHEIBUB, Zairo. Instituições e valores. As dimensões da democracia na visão da elite brasileira. Revista Brasileira de Ciências Sociais, n. 31, ano 11, p. 83- 110, 1996.

LIMA Júnior, Olavo Brasil. Instituições políticas democráticas: o segredo da legitimidade. Rio de Janeiro: Zahar, 1997.

MENEGUELLO, Rachel. Eleitorado e reforma. In: BENEVIDES, M. V; KERCHE, F.; VANNUCHI (Orgs.). Reforma política e cidadania. São Paulo: Editora Fundação Perseu Abramo, p. 344- 363, 2003.

MILL, John Stuart. Considerações sobre o governo representativo. Brasília: UNB, 1981.

OLIVEIRA, Evelina Antunes F. As associações comunitárias em Alagoas. Maceió: EDUFAL, 1997.

QUIRINO, Célia Galvão. Sobre a liberdade e a igualdade. In: TOCQUEVILLE, A.. Os clássicos da política. Cap. 5, p. 151-188, 1989.

REIS, Fábio Wanderley; MACHADO, Mônica M. Regiões, classe e ideologia no processo eleitoral brasileiro. Revista Lua Nova, n. 26, p. 81- 218, 1992.

SANDOVAL, Salvador A. M. O comportamento político como campo interdisciplinar de conhecimento: a reaproximação da Sociologia e da Psicologia Social. In: LHULLIER, Louise et al (Org.). Estudos sobre comportamento político: teoria e pesquisa. Florianópolis: Letras

Contemporâneas, p. 13-23, 1997.

SANTOS, Wanderley Guilherme dos. A universalização da democracia. In: BENEVIDES, M.V; KERCHE, F.; VANNUCHI (Orgs.). Reforma política e cidadania. São Paulo: Editora Fundação Perseu Abramo, p. 33-43, 2003.

SARTORI, Giovanni; MORLINO, Leonardo. La comparación en las ciencias sociales. Madrid: Alianza Editorial, 1994.

TOCQUEVILLE, Alexis. A democracia na América. Belo Horizonte: Itatiaia, 1964. 
WEFFORT, Francisco. Por que democracia? São Paulo: Brasiliense, 1984.

<www.tse.gov.br>. Acesso em: em 24 jul. 2003.

<www.ibam.org.br>. Acesso em: 10 ago. 2003. 